\title{
The impact of hoist sling materials on interface pressure whilst sitting in healthy volunteers and wheelchair users: A comparative study
}

Webb, J.1, Twiste, M.2, Walton, L.A.3, Hogg, $P_{.3}$

1. Occupational Therapy, School of Health Sciences, University of Salford, UK

2. UNIPOD - United National Institute for Prosthetics \& Orthotics Development, School of Health Sciences, University of Salford, UK

3. Diagnostic Imaging, School of Health Sciences, University of Salford, UK

Corresponding Author: Jo Webb

Address: Allerton C404, Allerton Building, University of Salford, Salford, M5 4WT

Email: j.webb@salford.ac.uk

Telephone Number: 01612950701

Abstract:

Aim of the study:

To evaluate the effect of three sling fabrics on gluteal interface pressure whilst sitting in a population of wheelchair users and to compare these to data previously collected in a pilot study with a healthy population.

Materials and methods: A repeated measures experimental design was used with 32 adult wheelchair users (15 women, 17 men). Healthy population pilot study consisted of 61 participants (51 women, 10 men) recruited from staff and students at The University of Salford.

Methods: Gluteal pressures at six pressure zones were recorded using the X-sensor PX100 pressure sensor at 30 second intervals for 10 minutes. Data were collected in 4 conditions with participants seated in a standardised chair, followed by the chair with slings made of three different fabrics.

Results: The spacer fabric reduced the mean gluteal pressure more effectively than slipfit and polyester $(p=0.014$ and $p=0.01$ respectively, $95 \% \mathrm{Cl})$ and reduced peak pressure at the left 
ischial tuberosity and coccyx when compared to the slipfit $(p=0.003$ and $p=0.005)$ with the wheelchair users. When comparing data with the pilot study, the mean gluteal pressure and peak pressures at the ischial tuberosities and coccyx were significantly higher in the wheelchair user group $(p<0.005)$.

Conclusion: The fabric identified as the most effective in reducing mean and peak pressures in both groups was the spacer fabric, suggesting that a spacer fabric sling is more likely to reduce the risk of pressure ulcer development.

This research did not receive any specific grant from funding agencies in the public, commercial, or not-for-profit sectors.

\section{Introduction}

A pressure ulcer is defined as a localised injury to the skin or underlying tissue, occurring because of pressure, or pressure in combination with shear and usually over a bony prominence [1]. Pressure ulcers are a common, costly and physically debilitating health complication, affecting people in both acute care and the community. National prevalence surveys conducted in the USA reported a prevalence rate of $15.5 \%$ among healthcare facilities [2], whilst Europe has a reported prevalence rate of $18.1 \%$ [3]. Any patient can develop a pressure ulcer; however, they are more likely to occur in people who are seriously ill, have a neurological condition, reduced sensation, limited mobility, nutritional deficiency, the inability to reposition themselves or significant cognitive impairment [4].

Pressure ulcers affect an individual's physical and psychological well-being, impacting negatively on their ability to carry out activities of daily living or leisure occupations, reducing their quality of life and levels of social interaction [5]. The development of a pressure ulcer can impact an individual's rehabilitation process, leading to extended hospital stays with the annual cost of treating pressure ulcers in the UK estimated to be between £1.4 and £2.5 billion [6]. According to Guy et al (2013) [7], The Department of Health has proposed that pressure ulcers 
could be eliminated in $95 \%$ of all NHS patients, identifying pressure ulcers as one of the four harms to be measured and monitored using the NHS Safety Thermometer [8].

Evidence based guidelines to reduce the risk of pressure ulcers in prolonged lying patients are extensive [1,4], however, guidance for prolonged sitting is less well established [9]. Wheelchair users or patients who sit for extended periods due to limited mobility have an increased risk of developing a pressure ulcer [10], as their weight is borne over a smaller surface area than when lying, with a major proportion of their body weight being supported by the ischial tuberosities, sacrum, upper thighs and buttocks [11]. As the most common sites for pressure ulcer development in a seated person are the sacrum and ischial tuberosities [3], the National Pressure Ulcer Advisory Panel (2007)[12] recommend that such individuals should be encouraged to reposition every 15 minutes to reduce the duration and magnitude of pressure over these sensitive areas.

Wheelchair users who use a hoist to transfer are lifted with a sling that supports their thighs, hips and back. It is generally recommended that the sling should be removed between procedures $[13,14]$, although in practice this is not always the case. Removing slings can be time consuming and sometimes difficult whilst maintaining good posture for the user and carer, whilst users often prefer to avoid being handled unnecessarily [15]. There are many designs of slings using a wide variety of fabrics; most commonly plain polyester, parachute silk (or "slipfit") and 'spacer' fabrics. Plain polyester knitted fabrics are hard wearing with some element of 2 way stretch and are commonly standard issue for sling provision. Slipfit fabrics are non-breathable, wafer-thin parachute silk style fabrics, with similar features to slide sheets being easier to insert and remove due to the reduction in friction, however the close knit has no stretch and little ventilation. Spacer fabrics are three dimensional knitted fabrics consisting of two separate knitted substrates which are joined together or kept apart by spacer yarns. Comprising an initial layer for moisture release, an interior layer for air flow, and a third outer layer for heat dissipation. The naturally ventilating properties of spacer fabric take moisture 
away from the skin and it's soft, cushioning characteristics reduce force, allowing 4-way stretch whilst remaining relatively light [16].

NICE (2014)[4] recognise that the use of medical equipment, including special seating or beds, can cause pressure ulcers with the National Pressure Ulcer Advisory Panel (NPUAP)(2016)[12] adding a "medical device induced pressure injury" to the staging classifications and the International guidelines including a section advising interventions for the prevention and treatment of medical device related pressure ulcers [17]. Results from the pilot study with healthy volunteers [18], identified the possibility that a sling, identified as a "medical device", could increase risk of pressure ulcer development if left in situ by creating a similar hammock effect as discussed by lizaka et al. (2009)[19].

This study evaluated the effect of different sling fabrics using the testing protocol established by Mellson and Richardson (2012) [18], within a population of wheelchair users. Results from the current study with the wheelchair users were compared with previous findings from the pilot study [18] to determine the impact of different sling fabrics on interface pressures between the 2 populations.

\section{Material and methods}

\subsection{Recruitment / participants}

This is an experimental study using a repeated measures design with 32 adult wheelchair users (15 women and 17 men) recruited from 2 wheelchair clinics in England, aged $55.3 \pm$ 13.9 years, with a mass of $84.2 \pm 18.9 \mathrm{~kg}$ and BMl of $29.97 \pm 6.8 \mathrm{~kg} / \mathrm{m}^{2}$. Data from the pilot study with healthy volunteers, consisting of 61 participants (51 women and 10 men), aged $44.3 \pm 11.4$ years, with a mass of $75.73 \pm 17.5 \mathrm{~kg}$ and $\mathrm{BMl}$ of $27.43 \pm 5.1 \mathrm{~kg} / \mathrm{m}^{2}$ [18] were used to calculate sample size. With $80 \%$ power $(p=0.05)$ a sample size of 32 was identified. 36 
participants were recruited to the study, however 4 withdrew due to poor health and unsuitability of the chair, leaving a sample size of 32 .

\subsection{Ethical approval}

Ethical approval was obtained from the University of Salford (reference HSCR12/18) and the NHS National Research Ethics Service (reference 12/YH/0309). Principal investigators at both centres screened potential participants against inclusion and exclusion criteria which included the ability to sit still for a minimum period of 16 minutes, be able to transfer in and out of a chair with assistance and excluded participants with an existing pressure ulcer.

\subsection{Procedure}

Participants wore suitable clothing to avoid creating artefactual pressure points, e.g. buttons over the seated area. They were seated on an adjustable height chair (Putnams coccyx posture chair, Putnam health Co Ltd, Devon, UK) with knees at approximately 90 degrees flexion. A six-minute settling time was used for this study, after which pressure readings commenced $[20,21]$ using the X-sensor PX100 from SUMED International.

Measurements were taken in four conditions, randomised to reduce systematic carry-over effects:

i. Control - Seated on chair with pressure mapping system only

ii. Condition A - Control plus sling in spacer fabric

iii. Condition B - Control plus sling in slipfit fabric

iv. Condition $\mathrm{C}-$ Control plus sling in polyester fabric

After the six-minute settling time, pressure readings were recorded every 30 seconds over ten minutes in each condition such that the participant was seated for 16 minutes in each condition. Interface pressure mapping was carried out in accordance with the International best practice guidelines [22] to ensure rigour and consistency in data collection, allowing 5 
minutes in between each condition for recovery. All data were collected in one clinic attendance.

\subsection{Equipment}

The sling fabrics were the same as those used in the pilot study [18], all three slings were manufactured in a comfort recline design to minimise multiple variables from different sling designs (product code 8E4400: PRISM Medical UK Ltd, Lancashire, UK).

X-Sensor Pressure Measurement System:

The X-sensor PX100 pressure sensor was used to measure the interface pressure over the gluteal region (i.e. buttocks and thighs). The mat consists of a $450 \mathrm{~mm} \times 450 \mathrm{~mm}$ flexible pad containing 1,296 individual capacitors (cells) that detect a signal when pressure is applied. Six pressure measurement zones were used:

- Mean pressure at gluteal region (buttocks and thighs)

- Peak pressure at left and right ischial tuberosities

- Peak pressure at left and right greater trochanters

- Peak pressure at the coccyx

\subsection{Data analysis}

Data analysis was conducted using SPSS (Version 23). Data were tested for normality using Kolmogorov-Smirnov's test (with Lilliefors significance correction where necessary). Differences in interface pressure measurements at the six pressure zones between the different fabrics and the control were analysed using a one way repeated measures analysis of variance (ANOVA). When comparing data from the wheelchair user population with the pilot (healthy) population, a mixed measures ANCOVA was used with a covariate for body mass as it was noted that the wheelchair user group had a significantly higher body mass. Findings from comparisons between the 2 groups (using the mixed measures ANCOVA) identified 
significant main effects in 4 of the pressure zones. These were further analysed using posthoc independent t-tests in Microsoft Excel 2013 with Bonferroni adjustment (Microsoft Corporation, Washington, USA). The peak pressures analysed were calculated using the peak pressure index (PPI) at the ischial tuberosities, greater trochanters and coccyx.

\section{$\underline{\text { 3.Results }}$}

\subsection{Analysis of wheelchair user population}

The one way repeated measures ANOVA on the different sling fabrics (given in Table 1) showed a significant main effect for mean gluteal interface pressure, $F(3,29)=4.78, p=0.008$, compared to the control condition. The spacer fabric reduced the mean gluteal interface pressure and this approached significance (spacer $p=0.06,95 \% \mathrm{Cl}$ ) but the slipfit and polyester fabrics had no effect ( $p=1$ for both fabrics, $95 \% \mathrm{Cl}$ ). Comparing fabrics, the spacer reduced the mean gluteal pressure more effectively than slipfit and polyester $(p=0.014$, and $p=0.01$ respectively, $95 \% \mathrm{Cl})$.

The fabrics had a varied effect on peak pressures, with the ANOVA on the different sling fabrics showing significant main effects for the left ischial tuberosity, $F(3,29)=5, p=0.006$, with the spacer fabric reducing peak pressures when compared to the slipfit; $p=0.003$. No fabrics altered the pressure at the left or right greater trochanter but the ANOVA showed significant main effects for fabric at the coccyx peak pressure, $F(3,28)=5.263, p=0.005$, with spacer fabric reducing the peak pressure when compared to slipfit $(p=0.005)$.

Table 1: Wheelchair user data - one way repeated ANOVA at six pressure zones (gluteal region, left ischial tuberosity, right ischial tuberosity, left greater trochanter, right greater trochanter and coccyx) $\left(\alpha>0.05,{ }^{*}<0.05,{ }^{* *}\right.$ $<0.01$ ).

\begin{tabular}{|c|c|c|c|c|}
\hline Pressure (mmHg) & $\begin{array}{c}\text { Control } \\
\text { Mean (SD) }\end{array}$ & $\begin{array}{c}\text { Spacer } \\
\text { Mean (SD) }\end{array}$ & $\begin{array}{c}\text { Slipfit } \\
\text { Mean (SD) }\end{array}$ & $\begin{array}{l}\text { Polyester } \\
\text { Mean (SD) }\end{array}$ \\
\hline Mean gluteal region & $\begin{array}{cc}43.06 & (6.56) \\
\llcorner & \alpha \\
\end{array}$ & $41.81 \quad(6.01)$ & $43.06 \quad(6.15)$ & $43.06 \quad(6.79)$ \\
\hline $\begin{array}{l}(n=32) \\
\text { Main effect } p<0.01\end{array}$ & & & ** & \\
\hline
\end{tabular}




\begin{tabular}{|l|ll|ll|lll|ll|}
\hline $\begin{array}{l}\text { Peak left ischial } \\
\text { tuberosity } \\
(n=32) \\
\text { Main effect } p<0.01\end{array}$ & 94.94 & $(36.54)$ & 82.66 & $(29.44)$ & 94.41 & $(36.95)$ & 91.59 & $(39.45)$ \\
\hline $\begin{array}{l}\text { Peak right ischial } \\
\text { tuberosity } \\
(n=32)\end{array}$ & 91.88 & $(39.24)$ & 82.31 & $(30.62)$ & 91.94 & $(35.41)$ & 84.88 & $(39.48)$ \\
\hline $\begin{array}{l}\text { Peak left greater } \\
\text { trochanter } \\
(n=32)\end{array}$ & 31.97 & $(7.67)$ & 31.03 & $(7.55)$ & 30.66 & $(6.86)$ & 30.53 & $(7.77)$ \\
\hline $\begin{array}{l}\text { Peak right greater } \\
\text { trochanter } \\
(n=32)\end{array}$ & 30.28 & $(7.09)$ & 31.13 & $(6.49)$ & 31.47 & $(7.89)$ & 29.75 & $(7.95)$ \\
\hline $\begin{array}{l}\text { Peak coccyx } \\
(n=31) \\
\text { Main effect } p<0.01\end{array}$ & 84.09 & $(43.96)$ & 74.71 & $(47.06)$ & 97.94 & $(56.41)$ & 82.77 & $(52.02)$ \\
\hline
\end{tabular}

\subsection{Analysis of healthy population}

Within the healthy population, the one way repeated measures ANOVA demonstrated statistical significance of the main effect of the sling fabrics (given in Table 2) for mean gluteal pressure, $F(3,58)=9.19, p<0.001$, and peak pressure at the right ischial tuberosity, $F(3,58)=9.14, p<0.001$, therefore demonstrating some similarities of the impact of the sling fabrics in both groups on mean interface pressure and some impact on one or both ischial tuberosities. However, although the coccyx highlighted statistically significant differences with the disabled population, this was not demonstrated with the healthy population group, where significance was noted at the right ischial tuberosity.

Table 2: Healthy population data - one way repeated ANOVA at six pressure zones (gluteal region, left ischial tuberosity, right ischial tuberosity, left greater trochanter, right greater trochanter and $\operatorname{coccyx})\left({ }^{*}<0.05,{ }^{* *}<0.01,{ }^{* * *}\right.$ $<0.001)$.

\begin{tabular}{|l|c|c|c|c|}
\hline $\begin{array}{l}\text { Pressure (mmHg) } \\
\mathrm{n}=61\end{array}$ & $\begin{array}{c}\text { Control } \\
\text { Mean (SD) }\end{array}$ & $\begin{array}{c}\text { Spacer } \\
\text { Mean (SD) }\end{array}$ & $\begin{array}{c}\text { Slipfit } \\
\text { Mean (SD) }\end{array}$ & $\begin{array}{c}\text { Polyester } \\
\text { Mean (SD) }\end{array}$ \\
\hline
\end{tabular}




\begin{tabular}{|c|c|c|c|c|}
\hline & $36.57 \quad(3.87)$ & 35.56 & 36.43 & $36.02 \quad(4.19)$ \\
\hline $\begin{array}{l}\text { Mean gluteal region } \\
(\mathrm{n}=61)\end{array}$ & $L_{* * *}$ & $* * \star$ & 故 & \\
\hline $\begin{array}{l}\text { Peak left ischial } \\
\text { tuberosity }(n=60)\end{array}$ & 67.37 (16.97) & $60.67(14.75)$ & $68.3(17.91)$ & $66.6(21.70)$ \\
\hline Peak right ischial & $65.03 \underbrace{(16.37)}$ & $58.43(13.88)$ & $\begin{array}{l}66.38(18.92) \\
\left.\right|_{* *}\end{array}$ & $64.82(19.65)$ \\
\hline & & $L$ & $* \star *$ & $」$ \\
\hline $\begin{array}{l}\text { Peak left greater } \\
\text { trochanter }(n=49)\end{array}$ & $19.41 \quad(4.12)$ & $18.73 \quad(3.67)$ & $18.20 \quad(3.76)$ & $\begin{array}{|ll|}18.78 & (3.55) \\
\end{array}$ \\
\hline $\begin{array}{l}\text { Peak right greater } \\
\text { trochanter }(n=58)\end{array}$ & $19.03 \quad(4.97)$ & $19.41 \quad(5.68)$ & $18.95 \quad(4.94)$ & $\begin{array}{|ll|}19.74 & (4.81) \\
\end{array}$ \\
\hline Peak coccyx $(n=57)$ & $32.33(10.26)$ & $31.18 \quad(9.42)$ & $31.58(11.82)$ & $31.84 \quad(9.64)$ \\
\hline
\end{tabular}

\subsection{Comparison of wheelchair population with healthy population}

On comparison of data, higher recordings of interface pressures were noted at all 6 pressure zones in the wheelchair user group (see Figure 1). These differences were explored further using a mixed measures ANCOVA with covariate for body mass to compare the differences in interface pressures between the two populations. Results showed statistical significance for the mean gluteal region and peak pressures at the ischial tuberosities and coccyx between both groups. Further exploration using post-hoc independent t-tests at the 5 pressure zones identified with significant effects using the ANCOVA between populations, demonstrated statistical significance at all sites examined, $p<0.005$ (see Figure 1 and Table 3). 
Interface pressures at 6 pressure zones in both populations

aControl a Spacer m Slipfit a Polyester

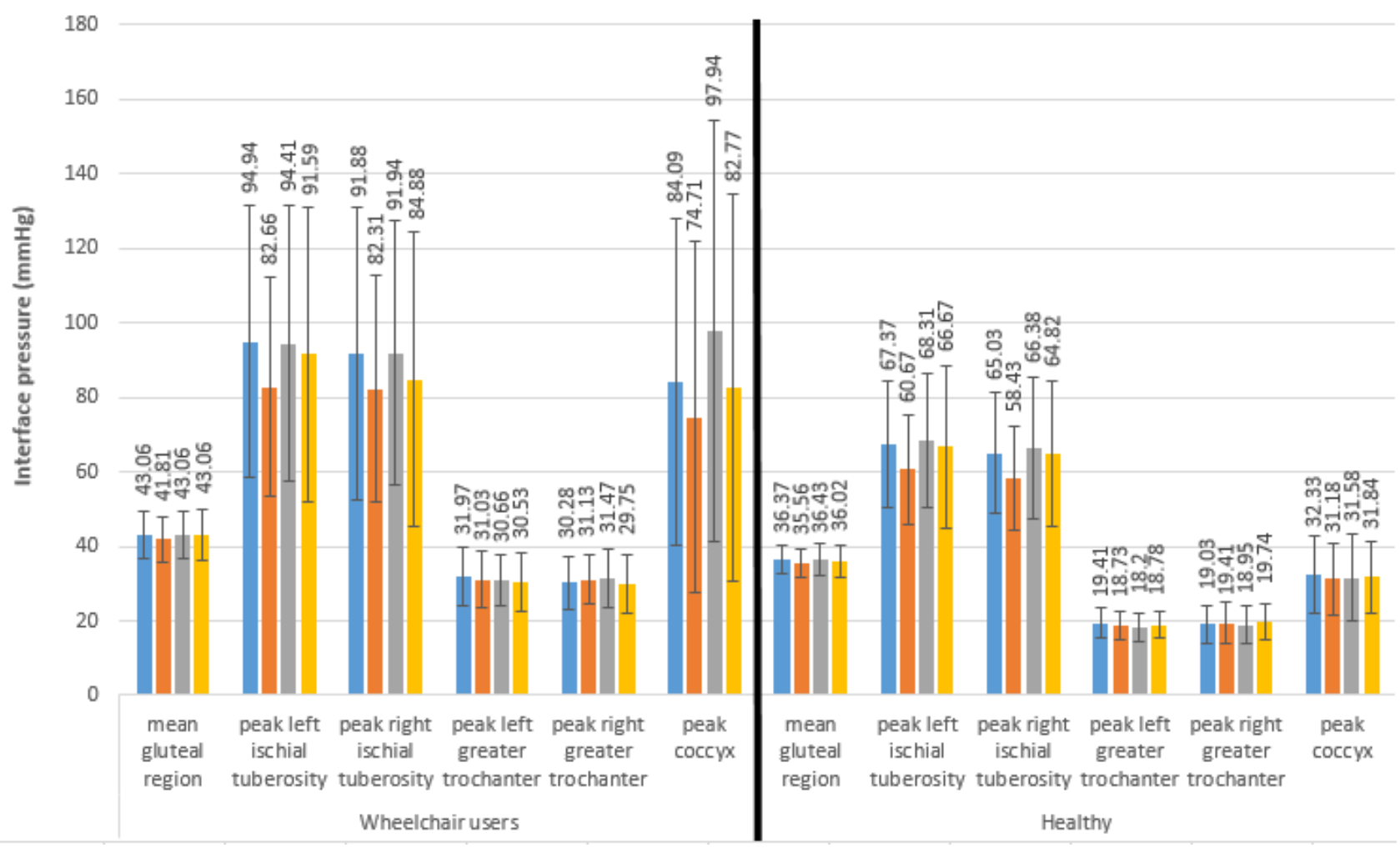

Figure 1: Interface pressure measurements of both populations at six pressure zones (gluteal region, left ischial tuberosity, right ischial tuberosity, left greater trochanter, right greater trochanter, coccyx).

Table 3: Independent t-test $\mathrm{p}$ values comparing disabled population with healthy population at identified pressure zones (gluteal region, left ischial tuberosity, right ischial tuberosity, coccyx).

\begin{tabular}{|l|l|l|l|l|}
\hline Fabric & $\begin{array}{c}\text { Mean gluteal } \\
\text { region } \\
\text { p value }\end{array}$ & $\begin{array}{c}\text { Peak left } \\
\text { ischial } \\
\text { tuberosity } \\
\text { p value }\end{array}$ & $\begin{array}{c}\text { Peak right } \\
\text { ischial } \\
\text { tuberosity } \\
\text { p value }\end{array}$ & $\begin{array}{c}\text { Peak coccyx } \\
\text { p value }\end{array}$ \\
\hline Control & $<0.001$ & $<0.001$ & $<0.001$ & $<0.001$ \\
\hline Spacer & $<0.001$ & $<0.001$ & $<0.001$ & $<0.001$ \\
\hline Slipfit & $<0.001$ & $<0.001$ & $<0.01$ & $<0.001$ \\
\hline Polyester & $<0.001$ & $<0.001$ & $<0.01$ & $<0.01$ \\
\hline
\end{tabular}

\section{Discussion}


The results show that different sling fabrics left underneath an individual can have an impact on interface pressure, and the choice of sling should be considered carefully for those at high risk of pressure ulcer development, particularly for the in-situ sling design. The peak pressure measured at different pressure zones differed between the wheelchair users and healthy volunteers. The Wheelchair users demonstrated a significant difference in overall mean pressure within the gluteal region and the coccyx (a common site for pressure ulcer development). The wheelchair user population demonstrated meaningful differences in overall mean pressure between the spacer and slipfit fabrics at the coccyx. As with the healthy population study, the increase in pressure predicted by clinical convention was not found; two fabrics (spacer and polyester) showed a decrease in mean pressure, and the spacer fabric reduced peak pressure at the ischial tuberosities and coccyx relative to no sling (control).

The reduction in mean gluteal interface pressure by the spacer and polyester fabrics could be explained by the nature of the materials as both have some element of two-way stretch. This property allows the fabrics to adapt to the participants' shape, thereby increasing the surface area and reducing pressure overall. In contrast, the slipfit fabric is very fine, which makes it easier to fit, but it does not stretch. This may create a 'hammock effect' resulting in reduced surface area between the participant and the seat surface [23], demonstrated by the significantly higher pressures recorded in both populations when compared to the spacer. Additionally, because the slipfit fabric is non-breathable, local moisture levels could increase, contributing to the microclimate and increasing risk factors in the formation of pressure ulcers [23].

The significantly higher peak pressures recorded at the coccyx in the wheelchair user group when compared with the healthy population are worth noting and support previous findings in paraplegic and tetraplegic patients [24, 25]. Although the wheelchair users involved in this study had no spinal injuries, and had a range of pathologies, these similar findings reflect a deviation from a normal sitting posture (in healthy people) where a significant proportion of 
body mass is spread over a larger gluteal area. The differences in body mass between the healthy and disabled population do not explain the observed differences in peak pressures: an ANCOVA was performed to control for body mass as a co-variate in this study. Results identify that the wheelchair users sit differently to the healthy population, and recent studies by Linder-Ganz and Gefen (2008)[26] indicate that even a small increase in surface interface pressure during sitting could be an indication of tissue deformation and higher levels of internal pressure at the bony interface. This deep tissue damage can be difficult to identify on the skin surface, often going unnoticed until the skin breaks down resulting in a deep tissue injury [12].

Muscle can be damaged by pressures exceeding $60 \mathrm{mmHg}$ lasting for more than an hour [27]. In the wheelchair user group, mean peak pressures recorded in the control condition (i.e. sitting on the chair alone) were $94.94 \mathrm{mmHg}$ and $91.88 \mathrm{mmHg}$ at the left and right ischial tuberosities respectively, and $84.09 \mathrm{mmHg}$ at the coccyx and are therefore potentially damaging. The slipfit and polyester fabrics made no differences to this, but when the spacer fabric was used the mean pressures fell towards this threshold. The standard deviation of the mean values and the wide $95 \%$ confidence intervals indicate that this reduction was not universal, but does raise the possibility that clinically significant reductions in peak pressure may be achievable for some patients.

In considering these results, several limitations need to be taken into account. Data from the pilot study with healthy participants [18] were used to inform a sample size calculation. The healthy participants were compared to a disabled population in this paper. Comparing the data of two groups with very different sample sizes may have increased the likelihood of type II error; a non-significant result when a difference may exist [30]. There were a range of disabilities and levels of mobility included in the wheelchair user group, and it is not known where these conditions differentially influenced the measured peak and mean pressures.

Finally, measurements were taken over a relatively short time period, in comparison to the prolonged periods that many wheelchair users sit on sling fabrics (often most of the waking 
day). Although steps were taken to ensure identification of the optimal testing protocol to establish the short-term effects of the sling fabric, further studies need to consider whether these changes are maintained for longer periods.

\section{$\underline{\text { 5.Conclusion }}$}

In contrast to moving and handling guidance $[14,15,28]$, and contrary to the belief that sling fabrics may increase the risk of pressure ulcer development $[28,29]$, this study identified that some fabrics can reduce peak pressures and may therefore reduce the risk of pressure ulcer development. The fabric identified as the most effective in reducing peak pressures in both populations of those evaluated was a breathable material with two-way stretch (spacer fabric). Results suggest that if a sling needs to be left in situ then the spacer fabric is more likely to reduce the risk of pressure ulcer development. These findings contribute to the evidence base to aid health care professionals in clinical decision making when recommending slings and in the education and promotion of safe handling techniques for people with reduced mobility.

\section{References}

[1] European Pressure Ulcer Advisory Panel and National Pressure Ulcer Advisory Panel. Pressure Ulcer Prevention (2009): Quick reference guide. Washington DC: National Pressure Ulcer Advisory Panel.

[2] Vangilder C, Amlung S, Harrison P, Meyer S (2008) Results of nine international pressure ulcer prevalence surveys:1989 to 2005. Ostomy and Wound Management; 54:40-54.

[3] Vanderwee K, Clark M, Dealey C, Gunningberg L, Defloor T (2007) Pressure ulcer prevalence in Europe: a pilot study. Journal of Evaluation in Clinical Practice; 13:227-235.

[4] National Institute of Clinical Excellence (NICE) (2014) Pressure ulcers: Prevention and management of pressure ulcers (CG 179) NICE: London.

[5] Ryan IM (2006) Teamwork keeps the pressure off: the role of the occupational therapist in the prevention of pressure ulcers. Home Healthcare Nurse; 24(2):97-102.

[6] Dealey C, Posnett,J, Walker A (2012) The cost of pressure ulcers in the United Kingdom. Journal of Wound Care 21(6), 261-266.

[7] Guy H, Downie F, McIntyre L, Peters J (2013) Pressure ulcer prevention: making a difference across a health authority? British Journal of Nursing (Tissue Viability Supplement), Vol 22, No 12, S4-S13.

[8] The Health and Social Care Information Centre (2015) NHS Safety Thermometer: Patient harms and harm free care. England April 2014 - April 2015, official statistics. 
[8] Stockton L and Rithalia S (2007) Is dynamic seating a modality worth considering in the prevention of pressure ulcers? Journal of Tissue Viability; 17:15-21.

[10] Gefen A (2007) The biomechanics of sitting-acquired pressure ulcers in patients with spinal cord injury or lesions. International Wound Journal;4,222-31.

[11] Stockton L, Gebhardt KS, Clark M (2009) Seating and pressure ulcers: Clinical practice guideline. Journal of Tissue Viability; 18:98-108.

[12] NPUAP (2016) Pressure injury stages available at:

http://www.npuap.org/resources/educational-and-clinical-resources/npuap-pressure-injury-

stages/ (accessed $5^{\text {th }}$ October, 2016).

[13] Cooper P, Gray D (2002) Best practice for treating and managing pressure ulcers. Clinical Practice Development. Scotland.

[14] Thomson S, Jevon P (2009) Manual Handling - using a sling hoist. Nursing Times; 105(3):12-13.

[15] Hignett S (2003) Systematic review of patient handling activities starting in lying, sitting and standing positions. Journal of Advanced Nursing; 41(6):545-552.

[16] Bruer SM, Powell N, Smith G (2005) Three-dimensionally knit spacer fabrics: A review of production techniques and applications, JTATM; 4, 4, Summer.

[17] National pressure Ulcer Advisory Panel, European Pressure Ulcer Advisory Panel and Pan Pacific Pressure Injury Alliance. Prevention and treatment of Pressure Ulcers: Quick Reference Guide. Emily Haesler (Ed.). Cambridge Media: Osborne Park, Australia; 2014.

[18] Mellson J, Richardson N (2012) The impact of hoist sling fabrics on gluteal interface pressure while sitting in healthy individuals: a controlled pre-post test study. Am J SPHM; 2(3):79-86.

[19] lizaka S, Nakagami G, Urasaki M, Sanada H (2009). Influence of the "hammock effect" in wheelchair cushion covers on mechanical loading over the ischial tuberosity in an artificial buttocks model. Journal of Tissue Viability; 18:47-54.

[20] Al-Eisa E, Fenerty A, Egan DA, Crouse J. (2000) Measurement of sitting pressure under the ischium: A reliability study. RESNA Conference Proceedings; 20:357-359.

[21] Stinson M, Gillan C, Porter-Armstrong A (2013) A literature review of pressure ulcer prevention: weight shift activity, cost of pressure care and the role of the occupational therapist. British Journal of Occupational Therapy; 76(4):169-178.

[22] Interdisciplinary Conference on Posture and Wheeled Mobility (2014) International Best Practice Guidelines. BPG2: Clinical guidelines for the use of interface pressure mapping for seating.

[23] Kernozek W, Wilder PA, Amundson A, Hummer J (2002) The Effects of Body Mass Index on Peak Seat-Interface Pressure of Institutionalised Elderly. Archives of Physical Medicine; 83:868-871.

[24] Aissaoui R, Lacoste M, Danserau J (2001) Analysis of sliding and pressure distribution during a repositioning of persons in a similar chair. IEEE Trans Neural Syst Rehabil Eng; 9(2):215-24.

[25] Thorfinn J, Sjoberg F, Lidman D (2002) Sitting pressure and perfusion of buttock skin in paraplegic and tetraplegic patients, and in healthy subjects: A comparative study. Scand J Plast Reconstr Surg Hand Surg; 36:279-283.

[26] Linder-Ganz E, Gefen A (2008) Stress analyses coupled with damage laws to determine biomechanical risk factors for deep tissue injury during sitting. J Biomech Eng; 131(1):011003011003-13. Doi:10.1115/1.3005195.

[27] Dharmarajan TS, Ugalino JT (2002) Pressure ulcers: Clinical features and management. Hospital Physician; March: 64-71.

[28] National back Exchange (2005) The guide to the handling of people $5^{\text {th }}$ Edition (Smith J, editor) Backcare in collaboration with the Royal College of Nursing and the National Back Exchange.

[29] Baptiste A, McCleerey M, Matz M, Evitt CP (2008) Proper Sling Selection and application While Using Patient Lifts. Rehabilitation Nursing: 33,1,22-32.

[30] Field A (2005) Discovering statistics using SPSS:(and sex, drugs and rock'n'roll) London : SAGE 2nd ed. 2005 
